\title{
Costs of plasticity: responses to desiccation decrease post-metamorphic immune function in a pond-breeding amphibian
}

\author{
Stephanie S. Gervasi* and Johannes Foufopoulos
}

School of Natural Resources \& Environment, The University of Michigan, 440 Church Street, Ann Arbor, Michigan 48109, USA

\begin{abstract}
Summary
1. Phenotypic plasticity may allow an organism to respond to temporally variable opportunities for growth and risks of mortality. However, life-history theory assumes that there are often trade-offs between the benefits afforded by plasticity in one trait and the consequences of that plasticity on other traits that affect fitness. In organisms with a complex life cycle, trade-offs may occur between larval and post-metamorphic traits.

2. Many amphibians metamorphose in temporary ponds, and may accelerate larval development to avoid mortality when a pond desiccates. A younger age at metamorphosis often results in reduced body size, but may also facilitate a trade-off with physiological traits that are linked to fitness in the adult stage.

3. We investigated a potential trade-off between desiccation-driven acceleration of development rate and immune system responsiveness in a species that breeds exclusively in temporary ponds. We exposed Rana sylvatica (wood frog) tadpoles to four possible desiccation regimes and then assayed the cell-mediated immune response to a standardized foreign antigen, phytohaemagglutinin (PHA), injected 3 weeks after metamorphosis. We also quantified total leucocyte numbers from haematological smears to obtain a secondary measure of individual immunological condition.

4. Animals exposed to desiccation had shorter development times, weaker cellular immune system responses to PHA and lower total leucocyte numbers than animals from control groups. Both measures of immune response showed a decrease with increasing severity of the desiccation treatment.

5. It is currently unclear whether the observed depression in immune response is transient or permanent. However, even temporary periods of immune system suppression shortly after metamorphosis may lead to greater susceptibility to opportunistic pathogens or parasites.
\end{abstract}

Key-words: ephemeral environment, phenotypic plasticity, immune system, Rana sylvatica

\section{Introduction}

Many organisms that exploit variable environments display phenotypic plasticity in life-history traits that are related to fitness. For example, growth and development rates often vary based on prevailing ecological conditions, and influence an individual's size and age at maturity (Roff 1992; Stearns 1992). Central to life-history theory is the assumption that trade-offs frequently exist between the benefits afforded by plasticity in one trait and the consequences of that plasticity on other traits that affect fitness (Stearns 1976, 1989a,b, 1992; Newman 1992; Roff 1992).

*Correspondence and present address: Department of Zoology, Oregon State University, 3029 Cordley Hall, Corvallis, OR 97331, USA. E-mail: gervasis@science.oregonstate.edu
Organisms that undergo a complex life cycle are particularly interesting models for examining the implications of phenotypic plasticity on life-history trade-offs in variable environments. Plasticity in growth and development rate influences the timing of metamorphosis and subsequent age and size at metamorphosis across a wide range of taxa [e.g. insects (Nylin, Wickman \& Wiklund 1989; Bradshaw \& Johnson 1995; Blanckenhorn 1998; Gotthard 1998; Lounibos 2001; Danks 2006), crustaceans (Twombly 1996; Hentschel \& Emlet 2000), fish (Reznick 1990) and amphibians (Wilbur \& Collins 1973; Wilbur 1980; Pfennig, Mabry \& Orange 1991; Rowe \& Ludwig 1991; Newman 1992; Morey \& Reznick 2004; Rudolf \& Rodel 2007)]. In general, body size is positively correlated with survival and fecundity, although a larger size often requires additional time for growth, and results in an older age at metamorphosis (Roff 1992; Stearns 
1992). As age at metamorphosis increases, so does the risk of mortality before reaching reproductive maturity (Stearns 1992). Theoretical studies suggest that the optimal timing of metamorphosis is based on maximizing growth and minimizing mortality in both the pre-metamorphic and post-metamorphic stages, or balancing the costs of a smaller body size against the risks of an older age at metamorphosis (Wilbur \& Collins 1973; Werner 1986; Rowe \& Ludwig 1991; Stearns 1992; Gotthard \& Nylin 1995; Abrams et al. 1996; Rudolf \& Rodel 2007). For example, when the risk of mortality in the larval stage is high relative to risks in the adult stage, earlier ontogenetic transitions are favoured. However, there are often varying degrees of risk associated with both stages, and these act antagonistically to influence the timing of metamorphosis. Recent models additionally consider the influence of time constraints (e.g. habitat duration and seasonality) on development time and, consequently, on the optimal size and age at metamorphosis (Rowe \& Ludwig 1991; Abrams et al. 1996; Lytle 2001; Rudolf \& Rodel 2007).

When risk of mortality in the larval environment increases as a function of time, a younger age at metamorphosis may be favoured in spite of costs associated with a smaller body size (Wilbur, Tinkle, \& Collins 1974; Wilbur 1980; Werner 1986; Rowe \& Ludwig 1991; Rudolf \& Rodel 2007). For example, some insect and many amphibian species undergo larval development in ephemeral ponds, and accelerate development rate to avoid mortality due to desiccation [e.g. insects (Chodorowski 1969; Juliano \& Stoffregen 1994), amphibians (Wilbur 1987; Newman 1988, 1992; Crump 1989; Denver 1997a; Morey \& Reznick 2000; Laurila \& Kujasalo 1999; Loman 1999; Loman \& Claesson 2003; Merila, Laurila \& Lindgren 2004; Rudolf \& Rodel 2007)]. This response is clearly beneficial and allows larvae to make an ontogenetic niche shift before a pond desiccates. However, trade-offs that confer immediate benefits in the larval environment may have long-term costs that accumulate in later stages. For example, amphibians that accelerate development trade-off a smaller body size for earlier metamorphose (Wilbur \& Collins 1973). Smaller bodied metamorphs may reach reproductive maturity later (Smith 1987), and show reduced fecundity (Howard 1980; Berven 1981) and survival (Berven \& Gill 1983; Morey \& Reznick 2000; Altwegg \& Reyer 2003).

The amphibian model is exceptionally useful for examining how habitat duration has shaped the evolution of developmental plasticity. Within seasonal environments, average hydroperiod is often variable. Plasticity may allow opportunistic larval growth in ponds with longer hydroperiods and earlier ontogenetic transitions in ponds with shorter hydroperiods (Newman 1992). In comparison to genetically fixed phenotypes, developmentally plastic individuals may have improved fitness because they increase their chances of attaining an optimal body size given the prevailing conditions (Newman 1992). Appropriate phenotypic responses in seasonally fluctuating environments depend on the presences of reliable environmental cues (Low 1976; West-Eberhard 1989). Proximate cues for desiccation may principally include an individual's proximity to the water surface or decreased swim- ming volume (Denver, Mirhadi \& Phillips 1998), although population density (Wilbur \& Collins 1973), presence of predators (Van Buskirk 1988; Skelly \& Werner 1990), water temperature (Smith-Gill \& Berven 1979), food availability (Travis 1984; Alford \& Harris 1988; Newman 1994) and pH (Gerlanc \& Kaufman 2005) also interact in complex ways to signal desiccation. The timing of cues may further impact metamorphosis. A species-specific developmental threshold must be achieved before an organism can respond to desiccation through accelerated development rate (Wilbur \& Collins 1973; Pfennig et al. 1991; Morey \& Reznick 2000; reviewed by Denver 1997a,b).

Environmental cues influence endocrine responses that control the timing of metamorphosis. Thyroid hormone (TH) is the primary morphogen in metamorphosis (Kikuyama et al. 1993). The major vertebrate stress hormones, corticosteroids, are also involved in morphogenesis, and may synergize with TH to accelerate development (Kikuyama et al. 1993). Both peak at metamorphic climax (the moment of front limb emergence) and facilitate the breakdown or reorganization of larval-type tissues and production of adult-type tissues (Rollins-Smith 1998). The impact of corticosteroids on development may be compounded when environmental conditions become unfavourable. As stress hormones, corticosteroids are also produced in response to external environmental stimuli. The response to environmental stimuli is regulated via the hypothalamus-pituitary-adrenal (HPA) axis and consists of elevation in plasma corticosteroid levels (defined as a 'stress response'). The functional role of the hormonal stress response is to divert stored energy toward the processes needed for immediate survival during periods of acute stress (non-essential processes such as reproduction, immune function and feeding are concomitantly inhibited by the stress response) (Sapolsky, Romero \& Munck 2000). Because of their role in metamorphosis, corticosteroids produced in response to environmental stimuli (such as desiccation) may facilitate precocious metamorphosis by synergizing with $\mathrm{TH}$ (Denver 1997a,b; Crespi \& Denver 2005).

While corticosteroids play a functional role in metamorphosis, they may also have negative effects on development and functioning of the immune system when elevated chronically or during early (i.e. larval) development. Chronically elevated corticosterone leads to immunosuppression (reviewed by Dhabhar 2002), and elevated levels of stress hormones present during early stages of development have been shown to increase basal circulating glucocorticoid levels and lead to a hyperactive HPA (stress) axis (Weinstock et al. 1992; McCormick et al. 1995). Since the stress axis and immune system are tightly coupled, early stage environmental factors that act as stressors could permanently modify the immune response.

Physiological consequences of reduced size and/or younger age at metamorphosis have been examined in several studies of amphibians (e.g. John-Alder \& Morin 1990; Goater, Semlitsch, \& Bernasconi 1993; Newman \& Dunham 1994; Beck \& Congdon 2000; Watkins 2001; Relyea 2002; Altwegg \& Reyer 2003). Some of these studies have demonstrated that 
indices of physical performance that may influence survival (e.g. jump distance, locomotor stamina and sprint speed) are reduced in animals that metamorphose earlier or at a smaller size (John-Alder \& Morin 1990; Goater et al. 1993; Beck \& Congdon 2000). Few studies have investigated how environmentally driven trade-offs may impact adult immune response (Stoks et al. 2006). The immune system is an organism's primary defence against pathogens and parasites, and as such, is integrally related to survival (Lochmiller \& Deerenberg 2000). Recent evidence suggests that a robust immune system is energetically and nutritionally costly to develop, maintain and operate (Lochmiller \& Deerenberg 2000). Furthermore, theoretical and empirical studies suggest the existence of trade-offs between investment in energetically demanding life-history processes (including growth) and immunocompetence (the ability of a host to prevent or control pathogenic or parasitic infection) (Sheldon \& Verhulst 1996; Lochmiller \& Deerenberg 2000; Norris \& Evans 2000). Since trade-offs that result in decreased physical performance or immune responsiveness impose mortality risks in the adult stage, they are likely to affect the optimal timing of metamorphosis, specifically by favouring longer development periods.

This is the first study to experimentally investigate the relationships among a larval stage environmental stressor (pond desiccation), development rate and immune system responsiveness in an amphibian. We tracked number of days to completion of metamorphosis as well as body size and mass of each individual to investigate the developmental response to a range of ecologically relevant desiccation treatments against a constant, high water level control group. We compared immune responsiveness across treatment groups by (i) quantifying a skin-swelling response to a standardized immune challenge; and (ii) obtaining total leucocyte counts from haematological smears.

\section{Methods}

\section{ANIMAL HUSBANDRY}

Experimental animals originated from two Rana sylvatica egg masses collected on 14 April 2006 from a pond in the Edwin S. George Reserve located in Livingston County, MI, USA. Eggs were transferred to the laboratory within $24 \mathrm{~h}$ of collection, and were temporarily maintained in 69 -L plastic tanks $(33 \mathrm{~cm}$ wide $\times 48 \mathrm{~cm}$ long $\times 35.5 \mathrm{~cm}$ deep) containing enough water to cover the eggs completely and mimicking natural oviposition depths in the natal pond. After hatching, larvae were randomly transferred to several 69-L tanks (filled at least $75 \%$ of capacity). Tadpole density was maintained at approximately 75 individuals per tank until most tadpoles reached Gosner stage 26 (Gosner 1960). All similarly sized stage 26 tadpoles were then transferred in groups of six to $19-\mathrm{L}(21.5 \mathrm{~cm}$ wide $\times 34 \mathrm{~cm}$ long $\times 21.5 \mathrm{~cm}$ deep) plastic tanks containing $10 \mathrm{~L}$ water. Animals were subsequently maintained at six individuals per tank until initiation of the experiment to avoid the confounding effects of density on development. From the available group of tanks, 24 aquaria that did not previously experience any individual mortality were chosen for the experiment and randomly assigned to a treatment. Experimental treatments were initiated when tadpoles reached Gosner stage 37 , which was a conservative estimate of the developmental threshold of responsiveness to desiccation. Gosner stage 37 falls within 'prometamorphosis' (stages 35-40) and is defined by the rapid differentiation of hind limbs (Glennemeier \& Denver 2002). There was no replacement of dead animals after the initiation of experimental treatments [and mortality overwhelmingly occurred at or after (not before) metamorphic climax]. Once tadpoles reached metamorphic climax (Gosner stage 42, identified by the emergence of front limbs), they were transferred to19-L tanks containing paper towels and shallow water. At completion of metamorphosis (marked by complete absorption of tail tissue), metamorphs were individually transferred to $1 \cdot 2-\mathrm{L}(16 \mathrm{~cm}$ wide $\times 16 \mathrm{~cm}$ long $\times 9 \mathrm{~cm}$ deep $)$ containers for 21 days.

All animals were housed in a climate-controlled laboratory on the University of Michigan campus at $21-23^{\circ} \mathrm{C}$ on a $12 \mathrm{~L}: 12 \mathrm{D}$ light regime and in accordance with approved institutional animal care protocol (University Committee on Use and Care of Animals Protocol No. 9078). Tanks were filled with dechlorinated tap water and were changed once a week. Food waste and debris were removed daily using a fine mesh net. Black plastic barriers were constructed around the sides of experimental tanks to prevent tadpoles from viewing investigators and to prevent tadpoles in adjacent tanks from viewing one another. Tadpoles were fed TetraFin goldfish crisps (Masterpet Corp. Ltd, Blacksburg, VA) ad libitum and metamorphosized individuals were fed with wingless fruitflies (Ed's Flymeat, Port Orchard, WA) ad libitum (c. 20-25 flies) every other day.

\section{DESICCATION SIMULATION}

To simulate pond desiccation, experimental tanks (each containing six tadpoles) were randomly assigned to one of four possible treatments; slow desiccation, moderate desiccation, rapid desiccation or control. Each treatment was replicated across six aquaria. All experimental tanks contained an initial volume of $10 \mathrm{~L}$, and water levels were adjusted over the duration of the experiment to account for evaporation losses. Water was removed from the slow desiccation group tanks at a rate of $0.5 \mathrm{~L}$ every second day. On days when no water was removed, water was disturbed to simulate water removal and maintain consistency of disturbance among treatments. Water was removed from the moderate desiccation group tanks at a rate of $0 \cdot 5 \mathrm{~L} \mathrm{~d}^{-1}$ for the first 7 days and $1 \mathrm{~L} \mathrm{~d}^{-1}$ every day thereafter. Rapid desiccation group tanks lost water at a rate of $1 \mathrm{~L}$ every day. Once water volume was reduced down to $1 \mathrm{~L}$ (at which point animals had just enough water to completely cover their dorsal surface) it was held constant until metamorphic climax. The amount of time spent at this minimal water level varied by treatment, with individuals in the slow desiccation treatment reaching metamorphic climax before the $1 \mathrm{~L}$ level in all cases. In the moderate and rapid desiccation regimes, the time spent in minimal water conditions before metamorphic climax did not exceed eight days, and only two individuals spent more than 6 days in the lowest water conditions. Water was maintained at a constant $10 \mathrm{~L}$ for the control treatment. Experimental desiccation regimes were within the ecologically relevant boundaries for this species. In Michigan, Rana sylvatica tadpoles occupy small, temporary ponds, and metamorphose $6-15$ weeks after hatching (Harding 1997). In comparison, our experimental animals completed metamorphosis within a range of $8-10$ weeks after hatching. The natural larval environment is seasonally and spatially variable with respect to water availability. Wood frogs breed synchronously shortly after snowmelt in late March and early April, and ponds may be completely desiccated by mid- to late summer, with high degrees of variation in hydroperiods (Harding 1997). The temporary nature of the larval environment usually precludes aquatic vertebrate predators. 
Therefore, desiccation is likely to play a principal role driving the reaction norm at metamorphosis.

\section{MEASUREMENTS}

Date at metamorphic climax (forelimb emergence) was recorded for all individuals. Weight (to the nearest $0 \cdot 1 \mathrm{~g}$ ) and snout vent length (SVL) (to the nearest $0.01 \mathrm{~mm}$ ) were taken at metamorphosis and $21 \mathrm{~d}$ after metamorphosis (just prior to initiation of the immune challenge). Effect of desiccation treatment on duration of development was determined by recording number of days from initiation of the desiccation treatment at Gosner stage 37 to completion of metamorphosis.

\section{IMMUNE CHALLENGE}

Immunological investment was measured by exposing all animals to a standardized immune challenge in the form of a single phytohaemagglutinin (PHA) injection (Sigma-Aldrich, St Louis, MO). PHA is a lectin derived from the red kidney bean, Phaseolus vulgaris, which induces a T-lymphocyte response and causes localized inflammation around the injection point. A larger inflammatory (skin-swelling) response to PHA indicates a stronger immune response. PHA challenges have been used extensively in birds (e.g. reviewed by Smits, Bortolotti \& Tella 1999) and increasingly in reptiles (Svensson, Sinervo \& Comendant 2001; Oppliger et al. 2004), but rarely in amphibians (Gilbertson et al. 2003).

We conducted the immune challenge $21 \mathrm{~d}$ after metamorphosis to avoid interference with temporarily elevated CORT levels during metamorphic climax (which causes breakdown of larval-type lymphocytes) and to ensure that the challenge was carried out on the adult-type immune system (Rollins-Smith 1998, 2001; pers. comm.). Approximately $40-50 \mu \mathrm{L}$ of PHA (from a starting volume of $1 \mathrm{mg}$ crystallized PHA diluted in $1 \mathrm{~mL}$ phosphate-buffered saline solution) were injected subcutaneously and ventrally into an individual's right thigh skin using a 1-cc, 31G,5/16' insulin syringe (Becton Dickenson, Franklin Lakes, NJ). Contralateral injections of PHA and saline control were logistically difficult due to small body sizes of metamorphs. However, preliminary trials showed that the dosage of PHA we used could elicit a measurable inflammatory response that was greater in magnitude than the swelling response to injection with an equal amount of a phosphate-buffered saline control. No dosage corrections for body mass were made, since individuals did not differ significantly in weight at metamorphosis (ANOva $P=0 \cdot 611$ ). We measured skin thickness using a fine-gauged spessimeter (Mitutoyo, Precision Graphic Instruments, Inc., Spokane, WA) accurate to the nearest $0.01 \mathrm{~mm}$. The average of three consecutive measurements was taken to minimize measurement error. The average standard deviation (error) for our spessimeter was calculated to be $\pm 0.03 \mathrm{~mm}$ ). Skin thickness measures taken at baseline, $24 \mathrm{~h}$, and $48 \mathrm{~h}$ post-injection (in our control group) showed that swelling response to PHA is greatest (and significantly different from baseline skin thickness) at $24 \mathrm{~h}$ (Fig. 1; ANOVA $P=0 \cdot 042$ ). Therefore, immune responsiveness to PHA was considered to be the difference in skin-swelling response from the base measurement to the 24-h measurement. Preliminary analyses revealed occasional negative differences in skin-swelling responses between base and 24-h measures (indicating a weaker skin thickness measurement after injection). Although negative values were not considered biologically meaningful, they were included in all PHA analyses to be statistically conservative and to avoid any correction biases.

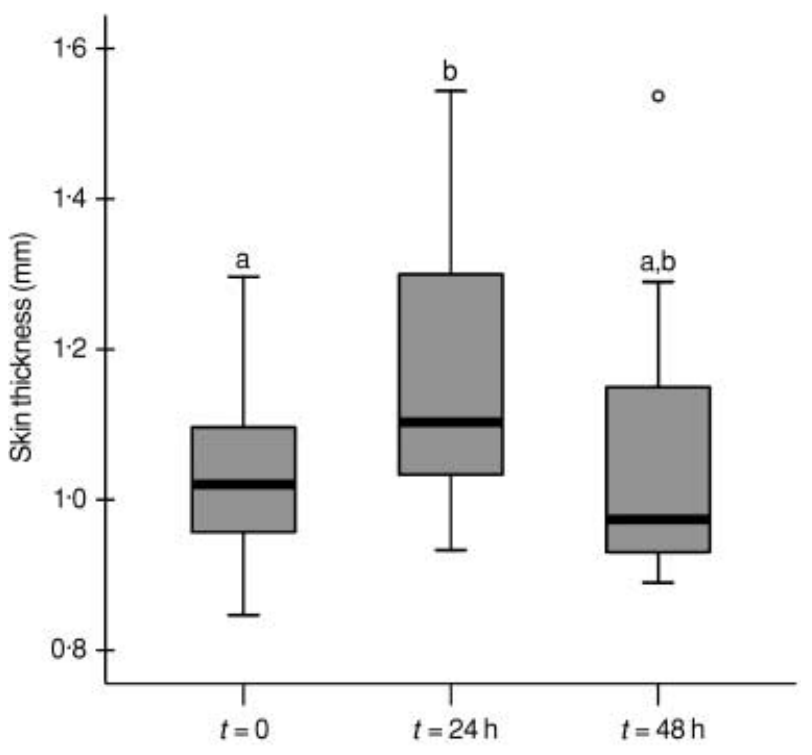

Fig. 1. Average skin thickness measure at baseline skin measurement $(t=0)$, and $24(t=24 \mathrm{~h})$ and $48(t=48 \mathrm{~h})$ hours after PHA injection (control animals; $N=26$ ). Boxes define the interquartile range (IQR), horizontal lines represent the mean, and whiskers indicate the maximum and minimum values within 1.5 times the IQR. Open circles denote outliers within 1.5 and 3 times the IQR. Letters represent significantly different means (Tukey tests, $P \leq 0 \cdot 05$ ).

\section{LEUCOCYTE COUNTS}

Approximately $72 \mathrm{~h}$ after the 48 -h skin-swelling measurement, remaining animals were sacrificed by immersion in benzocaine solution (Sigma Aldrich, St Louis, MO) and dissected to obtain blood from the heart and brachial vein. Thin blood smears were fixed in methanol solution within 5-10 min of preparation and stained using a Hema 3 Staining Kit (Fisher Scientific, Kalamazoo, MI, USA). Due to the small volume of blood available from metamorphs, counts of total leucocyte numbers were based on an examination of 2000 red blood cells. Leucocyte counts were conducted by a single investigator to avoid observer biases. We identified lymphocytes, basophils, monocytes, eosinophils, neutrophils and thrombocytes based on morphology and colour according to Rouf 1969, Whitaker \& Wright 2001 and Schalm 1986. Four outliers (all with studentized residuals $>2$ ) were excluded from all leucocyte analyses. To evaluate the repeatability of our cell count method, we rescored 10 randomly selected smears with previously obscured identities. Repeatability of cell counts was high (Pearson's correlation; $r_{\text {total }}$ leucocytes $=0.825, r_{\text {lymphocytes }}=0.844, r_{\text {thrombocytes }}=0.858, r_{\text {basophils }}=0.875$ and $r_{\text {neutrophils }}=0.791$ ). Monocytes and eosinophils were excluded from analyses because they were rarely seen.

\section{STATISTICAL ANALYSIS}

Parametric tests were used unless assumptions of normality were not met. A mixed model ANOva was used to test for effects of treatment on (i) developmental response (days to metamorphosis); (ii) SVL and weight at metamorphosis as well as $21 \mathrm{~d}$ later; and (iii) differences in total and differential leucocyte counts. Aquaria were treated as our units of analysis. To determine the effect of water volume reduction on inflammatory immune response, we used a mixed model ANCOVA. We used a homogeneity of slopes test to check for 
an interaction between SVL, treatment and weight across treatments. Because these interactions were not significant, they were not included in the final model. The dependent variable for the ANCOvA was skin swelling (difference between baseline and $24 \mathrm{~h}$ post-injection skin thickness), the fixed factor in the analysis was treatment (with four levels), and covariates included weight and SVL, both taken prior to the immune challenge. Our analysis allowed for negative correlations among observations on animals in the same tank. We chose to include both SVL and weight as covariates, since they each represent different aspects of size (that are usually highly correlated), which could influence skin-swelling responses. If significance was detected in any of the ANOVAS or the ANCOVA, pairwise comparisons were made using a Tukey-Kramer post-hoc test, and significance levels reported reflect adjustments using the Tukey-Kramer adjustment for multiple comparisons. All statistical analyses were performed using the computer software packages, SPSS 14 (SPSS Inc., Chicago, IL) and SAs 9·1 (SAS Institute, Cary, NC) for Windows.

\section{Results}

\section{EFFECT OF DESICCATION ON TADPOLE DEVELOPMENT AND GROWTH}

Tadpoles responded to desiccation by accelerating developmental rate (Fig. $2 \mathrm{a} ; F_{3,20}=4.53, P=0.014$ ). Individuals in the moderate desiccation treatment group displayed significantly fewer days to completion of metamorphosis than control animals $(P=0.009)$. We also observed that (i) animals in the slow desiccation group always reached metamorphic climax before water was drawn down to the 1-L level; (ii) animals in the moderate desiccation group reached metamorphic climax within a range of 4 days before to 6 days after the 1-L threshold was reached; and (iii) animals in the rapid desiccation group reached metamorphic climax within a range of 1 day after to 8 days after the 1-L threshold was reached. Despite the difference in developmental time, there were no significant differences in SVL or weight at metamorphosis (SVL:

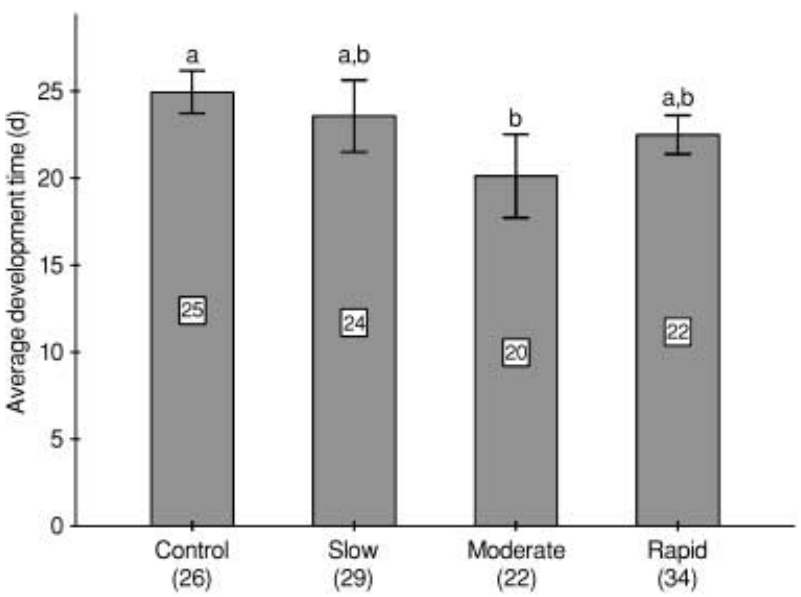

Fig. 2. Average number of days to completion of metamorphosis from initiation of the desiccation treatment at Gosner stage 37 across treatment groups. Tank means are given inside bars. Error bars $=\mathrm{SE}$. Letters represent significantly different group means (Tukey tests, $P \leq 0 \cdot 05)$. Sample sizes are given below treatment groups.
$F_{3,20}=1 \cdot 32, P=0 \cdot 295$, Weight: $\left.F_{3,20}=2 \cdot 32, P=0 \cdot 106\right)$. At 21 days after metamorphosis, just prior to the immune challenge, animals lost some weight but there were still no differences in SVL or weight across desiccation treatments (SVL: $F_{3,20}=0 \cdot 83, P=0 \cdot 495$, Weight: $F_{3,20}=1 \cdot 41, P=0 \cdot 269$ ).

\section{EFFECT OF DESICCATION ON POST-METAMORPHIC IMMUNE RESPONSE}

Strength of swelling response was significantly reduced in animals that experienced desiccation in the larval environment in a rate-dependent manner (Fig. $3 ; F_{3,20}=8 \cdot 81, P<0 \cdot 0006$ ). Individuals exposed to rapid and moderate desiccation treatments exhibited significantly weaker skin-swelling responses than individuals in the control group $(P<0.0001, P=$ $0 \cdot 0068$, respectively). Individuals in the rapid group also had weaker skin-swelling responses than individuals exposed to the slow desiccation treatment $(P=0.0019)$. There was a significant effect of the SVL covariate on swelling $\left(F_{1,85}=4.06, P=0.047\right)$ but not of weight $\left(F_{1,85}=0.46\right.$, $P=0.501)$, although these two measures were strongly and significantly correlated $(N=24, r=0.860, P<0 \cdot 0001)$. There was no significant interaction between treatment and weight $\left(F_{3,83}=1 \cdot 59, P=0.198\right)$ or treatment and $\operatorname{SVL}\left(F_{3,83}=1.91\right.$, $P=0 \cdot 135)$. Skin-swelling responses to PHA had a weak, positive correlation with body length (Fig. 5a; $N=24, r=$ $0 \cdot 323, P=0 \cdot 124$ ) and mass (Fig. 5b; $N=24, r=0 \cdot 287, P=$ $0 \cdot 173)$ taken prior to the immune challenge and a stronger, significant correlation with development time $(N=24, r=$ $0.552, P=0.005)$. Total leucocyte counts were also reduced by desiccation treatments (Fig. $4 ; F_{3,19}=3 \cdot 60, P=0 \cdot 032$ ). Individuals exposed to the rapid desiccation treatment had significantly fewer total leucocytes than individuals in the control group $(P=0 \cdot 0272)$. No significant differences were detected between differential leucocyte counts.

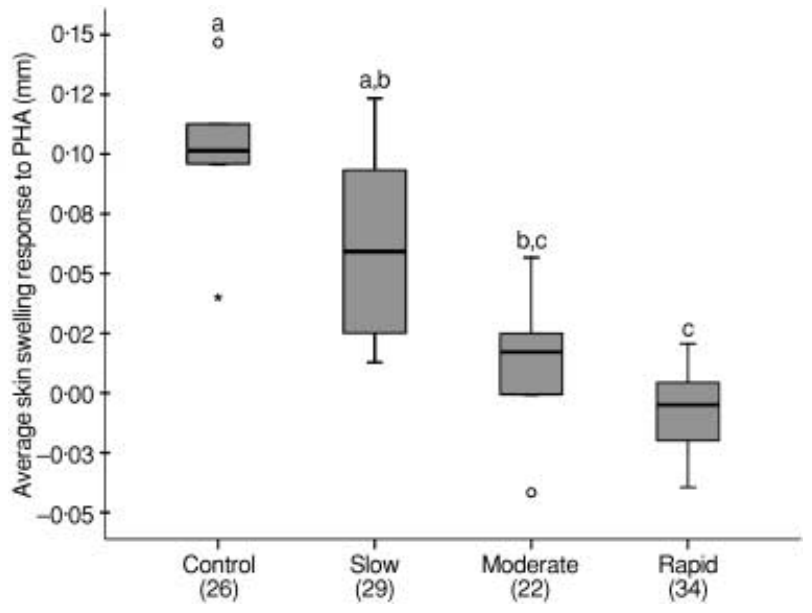

Fig. 3. Average skin-swelling response to PHA across treatment groups. Tank means are given displayed. Boxes define the interquartile range (IQR), horizontal lines represent the mean, and whiskers indicate the maximum and minimum values within 1.5 times the IQR. Open circles denote outliers within 1.5 and 3 times the IQR. Letters represent significantly different group means (Tukey tests, $P \leq 0 \cdot 05$ ). Sample sizes are given below treatment groups 


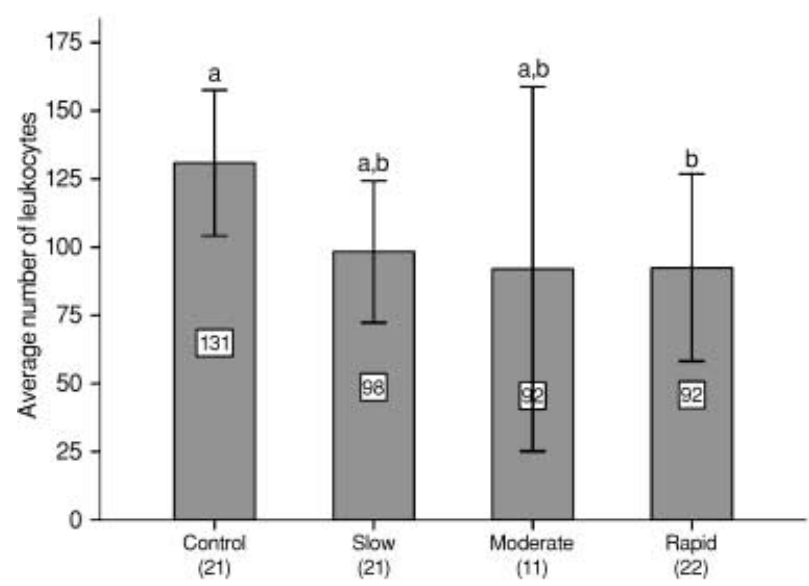

Fig. 4. Average number of leucocytes across treatment groups. Tank means are given inside bars. Error bars $=$ SE. Letters represent significantly different group means (Tukey tests, $P \leq 0 \cdot 05$ ). Sample sizes are given below treatment groups.

\section{Discussion}

Our results show that desiccation of the larval environment has a negative effect on two measures of immune system function in post-metamorphic animals; individuals exposed to desiccation generally developed faster than control animals, but had weaker skin-swelling responses to PHA and had lower total leucocyte numbers than individuals exposed to control conditions. In contrast with previous studies (Newman 1988; Crump 1989; Denver et al. 1998; Merila et al. 2004; Morey \& Reznick 2004), we did not observe a trade-off between age and size at metamorphosis in animals exposed to desiccation. We suspect that constant, favourable growth conditions (high food, low density) during early (pre-metamorphic) larval stages may have resulted in uniformly large prometamorphic tadpoles at the point when growth rates began to decelerate (just prior to metamorphic climax) (Wilbur \& Collins 1973; Collins 1979). While individuals may have continued to capitalize on opportunities for growth after initiation of the treatment regimes depending on the rate of water loss, most of the physiological changes occurring during prometamorphosis involve differentiation (i.e. development), rather than growth (Denver 1997b). Thus, the main effect of desiccation in our experiment was on development or differentiation rate, not growth rate. Accordingly, desiccation influenced age but not size or mass at metamorphosis.

Although age at metamorphosis was significantly reduced in the moderate desiccation regime, we did not detect a significant difference in development time between the control group and individuals exposed to rapid desiccation $(P=0 \cdot 209$; Fig. 2). One interpretation of this result is that the apparent decrease in development time in the moderate group may be attributable to a difference in the particular rate of water loss. Whereas both slow and fast desiccation treatments experienced a constant rate of water loss across development, the moderate group experienced an accelerated rate of water loss. Although animals reached the minimum 1-L threshold
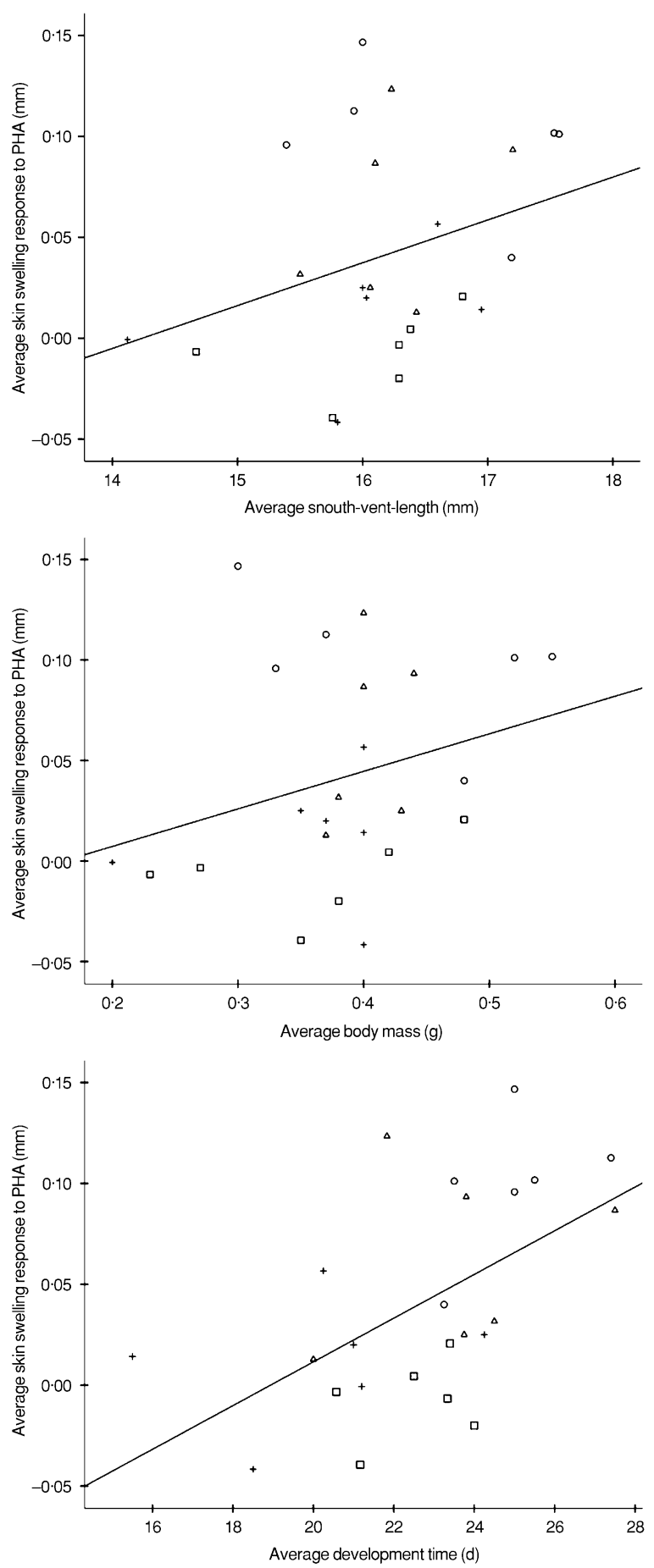

Fig. 5. (a) Relationship between average skin-swelling response to PHA and average body size taken prior to immune challenge $(N=24$, $r=0.323 ; P=0 \cdot 124)$. Solid line represents the fit line for all points. Circles $=$ control; triangles $=$ slow desiccation; plus marks $=$ moderate desiccation; squares = rapid desiccation. (b) Relationship between average skin-swelling response to PHA and average mass taken prior to immune challenge $(N=24 ; r=0.287 ; P=0.173)$. Solid line represents the fit line for all points. Circles $=$ control; triangles $=$ slow desiccation; plus marks = moderate desiccation; squares $=$ rapid desiccation. (c) Relationship between average skin-swelling response to PHA and average development time $(N=24 ; r=0 \cdot 552 ; P=0 \cdot 005)$. Solid line represents the fit line for all points. Circles = control; triangles = slow desiccation; plus marks = moderate desiccation; squares $=$ rapid desiccation. 
earlier in the rapid group than in the moderate group (day 9 after application of the treatment vs. day 13, simulating 'earlier drying' in the more severe regime), the effect of the variable rate of water loss prior to reaching this threshold may have imposed additional pressures on developing animals. We could not test whether the observed trend actually reflected an underlying difference in process; however, one possible explanation for the response could be that animals in the rapid group experienced the lowest levels of water sooner, and for a comparatively longer duration of time than individuals in the moderate treatment. Crump (1989) found that acceleration of development in response to habitat desiccation was most pronounced in larvae exposed to rapidly decreasing water levels, in comparison to constant low levels of water. We hesitate to use this as the only explanation, however, since there was no significant difference between individuals exposed to the rapid (constantly desiccating) regime and animals in the moderate (changing desiccation) group $(P=0.337)$ or between individuals exposed to the slow (constantly desiccating) regime and moderate desiccation treatments $(P=0 \cdot 099)$. Taken together with the fact that no differences in body size or mass emerged between the moderate desiccation regime and other treatments, we believe that at least some of the variation in response that contributes to a relatively unexpected non-significant difference between the control and rapid groups could result from experimental noise rather than significant differences in the desiccation regimes per se.

The observed pattern of post-metamorphic immune response across desiccation regimes may have been mediated directly or indirectly through the effect of desiccation on development. During metamorphosis, extensive tissue remodelling occurs, which is metabolically expensive (Sheridan \& Kao 1998). Since energetic resources are finite, it is possible that the development of features essential for terrestrial life (or immediate survival) takes precedence over processes that are not immediately essential (i.e. immune system development). Such an energetic trade-off might occur in conjunction with shorter developmental times (when differentiation rate is accelerated), and is to some extent supported by our observation of a significant positive correlation between skin-swelling response to PHA and development time ( $N=$ $24, r=0.552, P=0.005$; Fig. 5c). Alternatively, the reduction in post-metamorphic immune function may have resulted from the precocious elevation in corticosterone (CORT) concentrations prior to metamorphosis. Naturally elevated levels of CORT at metamorphic climax are functionally important (they facilitate destruction of larval-type lymphocytes, which are replaced by adult-type cells), although this results in temporary immunosuppression (Rollins-Smith 1998). Stressinduced metamorphosis, associated with elevation in CORT at an earlier developmental stage, may affect long-term integrity of the immune system by triggering a more dramatic loss of lymphocytes during the immune system transition (suggested in Rollins-Smith, Parsons \& Cohen 1988; RollinsSmith 1998). Furthermore, chronic stress or early-stage stress has been shown to impair normal development of the HPA axis and stress responses later in life (Weinstock et al. 1992; Cronje 2003). Since the HPA axis and immune system function cooperatively, this effect of desiccation could permanently modify regulation of the immune system.

Although we found that desiccation impacted two measures of immune function, PHA response and leucocyte numbers, these constitute only limited aspects of possible immune responses. Nonetheless, our results broadly suggest that the developmental response to habitat desiccation may indirectly contribute to increased risk of infection with parasites or pathogens. At least one emerging pathogen, Batrachochytrium dendrobatidis (chytrid fungus), causes disproportionate mortality in metamorphs of some anurans, possibly because this fungus primarily depends on keratinized epidermis newly available after metamorphosis (Rachowicz \& Vredenburg 2004). Increased susceptibility to such infection at an already vulnerable stage of life could have population-level implications that are particularly relevant, given the growing attention to emerging pathogens as a major driver of amphibian declines (reviewed by Daszak, Cunningham \& Hyatt 2003). Although rates of infection with chytrid fungus are relatively low in Rana sylvatica in comparison with other North American species (Ouellet et al. 2005; Longcore et al. 2007), factors that predispose individuals to infection may impact morbidity and mortality associated with the pathogen. The relationship between plastic responses to desiccation, immune responsiveness and infection rates is likely to be both stage-specific and species-specific.

To more fully understand the interaction between desiccation, immunity and infectious diseases, and to uncover whether the effect of desiccation is a short-term manifestation or a permanent outcome that compromises survival and reproductive success, we need to monitor immune responsiveness over longer periods of time. In a 3-year study, Altwegg \& Reyer (2003) found that individuals who metamorphosed at smaller sizes did not compensate for reduced body sizes by enhancing post-metamorphic growth. Similarly designed studies focusing on long-term examination of physiological traits affected by age and size at metamorphosis could be extremely revealing. Additionally, attention should be given to understanding of how currently available measures of immunocompetence relate to an impaired ability to fight infection. Finally, additional measures of immunity (e.g. innate immunity and antibody production) are needed to broaden our understanding of this phenomenon.

In conclusion, our results suggest a trade-off between a larval life-history trait and a post-metamorphic physiological trait, and a potential cost of plasticity. Given that the immune system is an organism's primary defence against invading pathogens and parasites, environmentally driven variation in immune response could have important impacts on an individual's health status and potential survival. The optimal timing of metamorphosis is likely to shift when the effects of desiccation impose additional risks in the adult (postmetamorphic) stage, such that longer development time is favoured to allow for uninterrupted immune system development. However, seasonal time constraints work antagonistically 
on the timing of metamorphosis, making it risky for animals to prolong development time in ephemeral larval environment (Rowe \& Ludwig 1991; Abrams et al. 1996; Rudolf \& Rodel 2007). We stress that an immune trade-off triggered by habitat desiccation is particularly relevant within a backdrop of changing local and global climate. More variable precipitation patterns and increased risk of drought over some continents (Houghton et al. 2001) could contribute to greater and more unpredictable annual and inter-seasonal variation in average hydroperiods of temporary ponds. Lethal, as well as sublethal, effects of environmentally induced physiological trade-offs should be considered in future studies, as both will ultimately affect potential costs of plasticity and the evolution of reaction norms in temporally variable environments.

\section{Acknowledgements}

We are grateful to R. Salhi, A.Hazel and C.Murdock for laboratory assistance. T. Raffel provided invaluable information on leucocyte identification and advice on use of PHA. M. Bernard provided tadpoles from the George Reserve. We also thank K. Welch for assistance with statistical analysis. This manuscript was greatly improved with advice from the Foufopoulos and Low laboratories, E. Crespi., B. Bancroft, A. Blaustein and J. Gervasi. Research was funded by a 2006 Grant-in-aid of Research from the Society for Integrative and Comparative Biology and by a Rackham Discretionary Fund from the University of Michigan.

\section{References}

Abrams, P.A., Leimar, O., Nylin, S. \& Wiklund, C. (1996) The effect of flexible growth rates on optimal sizes and development times in a seasonal environment. American Naturalist, 147, 381-395.

Alford, R.A. \& Harris, R.N. (1988) Effects of larval growth history on anuran metamorphosis. American Naturalist, 131, 91-106.

Altwegg, R. \& Reyer, H-U. (2003) Patterns of natural selection on size at metamorphosis in water frogs. Evolution, 57, 872-882.

Beck, C.W. \& Congdon, J.D. (2000) Effects of age and size at metamorphosis on performance and metabolic rates of southern toad, Bufo terrestris, metamorphs. Functional Ecology, 14, 32-38.

Berven, K.A. \& Gill, D.E. (1983) Interpreting geographic variation in lifehistory traits. Integrative and Comparative Biology, 23, 85-97.

Berven, K.A. (1981) Mate choice in the wood frog, Rana sylvatica. Evolution, 35, 707-722.

Blanckenhorn, W.U. (1998) Adaptive phenotypic plasticity in growth, development, and body size in the yellow dung fly. Evolution, 52, 1394-1407.

Bradshaw, W.E. \& Johnson, K. (1995) Initiation of metamorphosis in the pitcher-plant mosquito: effects of larval growth history. Ecology, 76, 2055 2065.

Chodorowski, A. (1969) The desiccation of ephemeral pools and the rate of development of Aedes communis larvae. Polish Archive for Hydrobiology, 16, 79-91.

Collins, J.P. (1979) Intrapopulation variation in the body size at metamorphosis and timing of metamorphosis in the bullfrog, Rana catesbeiana. Ecology, 60, $738-749$.

Crespi, E.J. \& Denver, R.J. (2005) Ancient origins of human developmental plasticity. American Journal of Human Biology, 17, 44-54.

Cronje, P.B. (2003) Foetal programming of immune competence. Australian Journal of Experimental Agriculture, 43, 1427-1430.

Crump, M.L. (1989) Effect of habitat drying on developmental time and size at metamorphosis in Hyla pseudopuma. Copeia, 1989, 794-797.

Danks, H.V. (2006) Key themes in the study of seasonal adaptations in insects II. Life cycle patterns. Applied Entomology and Zoology, 41, 1-13.

Daszak, P., Cunningham, A.A. \& Hyatt, A.D. (2003) Infectious disease and amphibian population declines. Diversity and Distributions, 9, 141-150.

Denver, R.J. (1997a) Proximate mechanisms of phenotypic plasticity in amphibian metamorphosis. American Zoologist, 37, 172-184.

Denver, R.J. (1997b) Environmental stress as a developmental cue: corticotropinreleasing hormone is a proximate mediator of adaptive phenotypic plasticity in amphibian metamorphosis. Hormones and Behavior, 31, 169-179.
Denver, R.J., Mirhadi, N. \& Phillips, M. (1998) Adaptive plasticity in amphibian metamorphosis: response of Scaphiopus hammondi tadpoles to habitat desiccation. Ecology, 79, 1859-1872.

Dhabhar, F.F. (2002) A hassle a day may keep the doctor away: stress and the augmentation of immune function. Integrative and Comparative Biology, $\mathbf{4 2}$, $556-564$.

Gerlanc, N.M. \& Kaufman, G.A. (2005) Habitat of origin and changes in water chemistry influence development of western chorus frogs. Journal of Herpetology, 39, 254-265.

Gilbertson, M.K., Haffner, G.D., Drouillard, K.G., Albert, A. \& Dixon, B. (2003) Immunosuppression in the northern leopard frog (Rana pipiens) induced by pesticide exposure. Environmental Toxicology and Chemistry, 22, 101-110.

Glennemeier, K.A. \& Denver R.J. (2002) Developmental changes in interrenal responses in anuran amphibians. Integrative and Comparative Biology, $\mathbf{4 2}$, $565-573$.

Goater, C.P., Semlitsch, R.D. \& Bernasconi, M.V. (1993) Effects of body size and parasite infection on the locomotory performance of juvenile toads, Bufo bufo. OIKOS, 66, 129-136.

Gosner, K.L. (1960) A simplified table for staging anuran embryos and larvae. Herpetologica, 16, 183-190.

Gotthard, K. \& Nylin, S. (1995) Adaptive plasticity and plasticity as an adaptation: a selective review of plasticity in animal morphology and life history. Oikos, 74, 3-17.

Gotthard, K. (1998) Life history plasticity in the satyrine butterfly Lasiommata petropolitana: investigating an adaptive reaction norm. Journal of Evolutionary Biology, 11, 21-39.

Harding, J.H. (1997) Amphibians and Reptiles of the Great Lakes Region. University of Michigan Press, Ann Arbor.

Hentschel, B.T. \& Emlet, R.B. (2000) Metamorphosis of barnacle nauplii: effects of food variability and a comparison with amphibian models. Ecology, 81, 3495-3508.

Houghton, J.T., Ding, Y., Griggs, D.J., Noguer, M., van der Linden, P.J., Dai, X., Maskell, K. \& Johnson, C.A. (eds) (2001) Climate Change 2001: The Scientific Basis. Cambridge University Press, Cambridge.

Howard, R.D. (1980) Mating behavior and mating success in wood frogs, Rana sylvatica. Animal Behaviour, 28, 705-716.

John-Alder, H.B. \& Morin, P.J. (1990) Effects of larval density on jumping ability and stamina in newly metamorphosed Bufo woodhousii fowleri. Copeia, 1990, $856-860$.

Juliano, S.A. \& Stoffregen, T.L. (1994) Effects of habitat drying on size at and time to metamorphosis in the tree hole mosquito Aedes triseriatus. Oecologia, 97, 369-376.

Kikuyama, S., Kawamura, K., Tatanka, S. \& Yamomoto, K. (1993) Aspects of amphibian metamorphosis - hormonal control. International Review of Cytology, 145, 105-148.

Laurila, A. \& Kujasalo, J. (1999) Habitat duration, predation risk and phenotypic plasticity in common frog (Rana temporaria) tadpoles. Journal of Animal Ecology, 68, 1123-1132.

Lochmiller, R.L. \& Deerenberg, C. (2000) Trade-offs in evolutionary immunology: just what is the cost of immunity? Oikos, 88, 87-98.

Loman, J. \& Claesson, D. (2003) Plastic response to pond drying in tadpoles Rana temporaria: test of cost models. Evolutionary Ecology Research, 5 , $179-194$.

Loman, J. (1999) Early metamorphosis in common frog Rana temporaria tadpoles at risk of drying: an experimental demonstration. Amphibia-Reptilia, 20, 421-430.

Longcore, J.R., Longcore, J.E., Pessier, A.P. \& Halteman, W.A. (2007) Chytridiomycosis widespread in anurans of northeastern United States. Journal of Wildlife Management, 71, 435-444.

Lounibos, P.L. (2001) Boom or bust development of a predatory mosquito in temporary aquatic habitats of Florida, USA. Israel Journal of Zoology, 47, $433-444$.

Low, B. (1976) The evolution of amphibian life histories in the desert. Evolution of Desert Biota (ed D.W. Goodall), pp. 149-195. University of Texas Press, Austin.

Lytle, D.A. (2001) Disturbance regimes and life history evolution. American Naturalist, 157, 525-536.

McCormick, C.M., Smythe, J.W., Sharma, S. \& Meaney, M.J. (1995) Sexspecific effects of prenatal stress on hypothalamic-pituitary-adrenal responses to stress and brain glucocorticoid receptor density in adult rats. Developmental Brain Research, 84, 55-61.

Merila, J., Laurila, A. \& Lindgren, B. (2004) Variation in the degree and costs of adaptive phenotypic plasticity among Rana temporaria populations. Journal of Evolutionary Biology, 17, 1132-1140.

Morey, S. \& Reznick, D. (2000) A comparative analysis of plasticity in larval development in three species of spadefoot toads. Ecology, 81, 1736-1749. 
Morey, S.R. \& Reznick, D.N. (2004) The relationship between habitat permanence and larval development in California spadefoot toads: field and laboratory comparisons of developmental plasticity. Oikos, 104, 172-190.

Newman, R.A. \& Dunham, A.E. (1994) Size at metamorphosis and water loss in a desert anuran (Scaphiopus couchii). Copeia, 1994, 372-381.

Newman, R.A. (1988) Adaptive plasticity in development of Scaphiopus couchii tadpoles in desert ponds. Evolution, 42, 774-783.

Newman, R.A. (1992) Adaptive plasticity in amphibian metamorphosis. Bioscience, 42, 671-678.

Newman, R.A. (1994) Effects of changing density and food level on metamorphosis of a desert amphibian, Scaphiopus couchii. Ecology, 75, 1085-1096.

Norris, K. \& Evans, M.R. (2000) Ecological immunity: life history trade-offs and immune defense in birds. Behavioral Ecology, 11, 19-26.

Nylin, S., Wickman, P.O. \& Wiklund, C. (1989) Seasonal plasticity in growth and development of the speckled wood butterfly, Pararge aegeria (Satyrinae). Biological Journal of the Linnaean Society, 38, 155-171.

Oppliger, A., Giorgi, M.S., Conelli, A., Nembrini, M. \& John-Alder, H.B. (2004) Effect of testosterone on immunocompetence, parasite load, and metabolism in the common wall lizard (Podarcis muralis). Canadian Journal of Zoology, 82, 1713-1719.

Ouellet, M., Mikaelian, I., Pauli, B.D., Rodrigue, J. \& Green, D.M. (2005) Historical evidence of widespread chytrid infection in North American amphibian populations. Conservation Biology, 19, 1431-1440.

Pfennig, D.W., Mabry, A. \& Orange, D. (1991) Environmental causes of correlations between age and size at metamorphosis in Scaphiopus multiplicatus. Ecology, 72, 2240-2248.

Rachowicz, L.J. \& Vredenburg, V.T. (2004) Transmission of Batrachochytrium dendrobatids within and between amphibian life stages. Diseases of Aquatic Organisms, 61, 75-83.

Relyea, R. (2002) Costs of phenotypic plasticity. American Naturalist, 159 272-282.

Reznick, D.N. (1990) Plasticity in age and size at maturity in male guppies (Poecilia reticulata): an experimental evaluation of alternative models of development. Journal of Evolutionary Biology, 3, 185-203.

Roff, D.A. (1992) The Evolution of Life Histories: Theory and Analysis. Chapman \& Hall, New York.

Rollins-Smith, L.A. (1998) Metamorphosis and the amphibian immune system. Immunological Reviews, 166, 221-230.

Rollins-Smith, L.A. (2001) Neuroendocrine-immune system interactions in amphibians. Implications for understanding global amphibian declines. Immunologic Research, 23, 273-280.

Rollins-Smith, L.A., Parsons, S.C., Cohen, N. (1988) Effects of thyroxine-driven precocious metamorphosis on maturation of adult-type allograft rejection responsiveness in early thyroidectomized frogs. Differentiation, 37, 180-185.

Rouf, M.A. (1969) Hematology of the leopard frog, Rana pipiens. Copeia, 1969, $682-687$.

Rowe, L. \& Ludwig, D. (1991) Size and timing of metamorphosis in complex life cycles: time constraints and variation. Ecology, 72, 413-427.

Rudolf, V.H.W. \& Rodel, M-O. (2007) Phenotypic plasticity and optimal timing of metamorphosis under uncertain time constraints. Evolutionary Ecology, 21, 121-142.

Sapolsky, R.M., Romero, L.M. \& Munck, A.U. (2000) How do glucocorticoids influence stress responses? Integrating permissive, suppressive, stimulatory, and preparative actions. Endocrine Reviews, 21, 55-89.

Schalm, O.W. (1986) Schalm's Veterinary Hematology, 4th edn. Lea and Febiger, Philadelphia.

Sheldon, B.C. \& Verhulst, S. (1996) Ecological immunology: costly parasite defenses and trade-offs in evolutionary ecology. Trends in Ecology and Evolution, 8, 317-321.
Sheridan, M.A. \& Kao, Y. (1998) Regulation of metamorphosis-associated changes in the lipid metabolism of selected vertebrates. American Zoologist, 38, 350-368.

Skelly, D.K. \& Werner, E.E. (1990) Behavioral and life-historical responses of larval American toads to an odonate predator. Ecology, 71, 23132322.

Smith, D.C. (1987) Adult recruitment in chorus frogs - effects of size and date at metamorphosis. Ecology, 68, 344-350.

Smith-Gill, S.J. \& Berven, K.A. (1979) Predicting amphibian metamorphosis. American Naturalist, 113, 563-585.

Smits, J.E., Bortolotti, G.R. \& Tella, J.L. (1999) Simplifying the phytohaemagglutinin skin-testing technique in studies of avian immunocompetence. Functional Ecology, 13, 567-572.

Stearns, S.C. (1976) Life-history tactics: a review of the ideas. Quarterly Review of Biology, 51, 3-47.

Stearns, S.C. (1989a) The evolutionary significance of phenotypic plasticity. Bioscience, 39, 436-445.

Stearns, S.C. (1989b) Trade-offs in life-history evolution. Functional Ecology, 3, 259-268.

Stearns, S.C. (1992) The Evolution of life Histories. Oxford University Press, New York.

Stoks, R., DeBlock, M., Slos, S., VanDoorslaer, W. \& Rolff, J. (2006) Time constraints mediate predator-induced plasticity in immune function, condition, and life history. Ecology, 87, 809-815.

Svensson, E., Sinervo, B. \& Comendant, T. (2001) Density-dependent competition and selection on immune function in genetic lizard morphs. Proceedings of the National Academy of Sciences of the United States of America, 98, 12561-12565.

Travis, J. (1984) Anuran size at metamorphosis: experimental test of a model based on intraspecific competition. Ecology, 65, 1155-1160.

Twombly, S. (1996) Timing of metamorphosis in a freshwater crustacean: comparison with anuran models. Ecology, 77, 1855-1866.

Van Buskirk, J. (1988) Interactive effects of dragonfly predation in experimental pond communities. Ecology, 69, 857-867.

Watkins, T.B. (2001) A quantitative genetic test of adaptive decoupling across metamorphosis for locomotor and life history traits in the pacific tree frog, Hyla regilla. Evolution, 55, 1668-1677.

Weinstock, M., Matlina, E., Maor, G.I., Rosen, H. \& McEwen, B.S. (1992) Prenatal stress selectively alters the reactivity of the hypothalamic-pituitary adrenal system in the female rat. Brain Research, 595, 195-200.

Werner, E.E. (1986) Amphibian metamorphosis: growth rate, predation risk, and the optimal size at transformation. American Naturalist, 128, 319341 .

West-Eberhard, M.J. (1989) Phenotypic plasticity and the origins of diversity. Annual Review of Ecology and Systematics, 20, 249-278.

Whitaker, B.R. \& Wright, K.N. (2001) Amphibian Medicine and Captive Husbandry. Krieger Publishing Co., Malabar.

Wilbur, H.M. \& Collins J.P. (1973) Ecological aspects of amphibian metamorphosis. Science, 182, 1305-1314.

Wilbur, H.M. (1980) Complex life cycles. Annual Review of Ecology and Systematics, 11, 67-93.

Wilbur, H.M. (1987) Regulation of structure in complex systems: experimental temporary pond communities. Ecology, 68, 1437-1452.

Wilbur, H.M., Tinkle, D.W. \& Collins, J.P. (1974) Environmental certainty, trophic level, and resource availability in life history evolution. American Naturalist, 108, 805-817.

Received 1 May 2007; accepted 21 August 2007

Handling Editor: Frank Messina 